\title{
PLYMOUTH
}

Title: One Year Surveillance of Body Mass Index and Cardiorespiratory Fitness in Primary School Children in North West England and the Impact of School

Deprivation Level

Author(s): Steven Mann, Matthew Wade, Michelle Jones, Gavin Sandercock, Chris Beedie and James Steele.

Copyright, publisher and additional information: This article has been accepted for publication in Archives of Disease in Childhood, 2018 following peer review, and the Version of Record can be accessed online at http://dx.doi.org/10.1136/archdischild-2018-315567

(C) Steven Mann, Matthew Wade, Michelle Jones, Gavin Sandercock, Chris Beedie and James Steele.

Reuse of this manuscript version (excluding any databases, tables, diagrams, photographs and other images or illustrative material included where another copyright owner is identified) is permitted strictly pursuant to the terms of the Creative Commons Attribution-Non Commercial 4.0 International (CC-BY-NC 4.0)

http://creativecommons.org

DOI: 10.1136/archdischild-2018-315567

Reference: Mann, S., Wade, M., Jones, M., Sandercock, G., Beedie, C. \& Steele, J. (2018). One Year Surveillance of Body Mass Index and Cardiorespiratory Fitness in Primary School Children in North West England and the Impact of School Deprivation Level, Archives of Disease in Childhood, http://dx.doi.org/10.1136/archdischild-2018-315567 


\section{One Year Surveillance of Body Mass Index and Cardiorespiratory Fitness in Primary School Children in North West England and the Impact of School Deprivation Level \\ Pre-print article (not peer reviewed) published on: \\ 13/11/2018 (doi: \\ 10.31236/osf.io/ijd9pv)}

Research conducted by the UK Active Research Institute

Citation: Mann, S., Wade, M., Jones, M., Sandercock, G., Beedie, C., \& Steele, J. (2018, November 13). One Year Surveillance of Body Mass Index and Cardiorespiratory Fitness in Primary School Children in North West England and the Impact of School Deprivation Level. https://doi.org/10.31236/osf.io/jd9pv 


\section{SUMMARY OF KEY FINDINGS}

- Both body mass index (BMI) and cardiorespiratory fitness (CRF) vary over the period of one year, including the school term and summer recess, in primary school children aged $9-10$ years.

- CRF significantly increased throughoutthe schoolyear, yet decreased back to baseline during the summer recess.

- This effect was influenced by school deprivation levels and pupils from the most deprived areas saw significantly greater reductions in CRF compared with pupils from affluent areas

- These results highlight a need for public health interventions aimed at increasing children's PA levels, particularly vigorous PA, to be targeted towards the summer holiday period. 


\title{
One Year Surveillance of Body Mass Index and Cardiorespiratory Fitness in Primary School Children in North West England and the Impact of School Deprivation Level
}

\author{
Steven Mann Ph.D ${ }^{1,2}$, Matthew Wade MSc ${ }^{1,3}$, Michelle Jones Ph.D ${ }^{4}$, Gavin Sandercock Ph.D ${ }^{5}$, Chris Beedie
} Ph.D ${ }^{6}$, James Steele Ph.D ${ }^{1,4}$

${ }^{1}$ ukactive Research Institute, London, UK; ${ }^{2}$ Centre for Applied Biological and Exercise Sciences, Faculty of Health and Life Sciences, Coventry University, Coventry, UK; ${ }^{3}$ School of Sport Health and Applied Science, St Mary's University, Twickenham, UK; ${ }^{4}$ School of Sport, Health, and Social Sciences, Southampton Solent University, UK; ${ }^{5}$ Department of Biological Sciences, University of Essex, Wivenhoe Park, Colchester CO4 3SQ; ${ }^{6}$ School of Human and Life Sciences, Canterbury Christ Church University, Canterbury, Kent, CTI IQU Contact for Correspondence jamessteele@ukactive.org.uk

Twitter: @jamessteeleii

\section{SCIENTIFIC ABSTRACT}

Objectives: Cardiorespiratory fitness (CRF) is independently associated with health and academic attainment in childhood and adolescence. Yet overweight/obesity remain the focus in public health policy. Surveillance of BMI and CRF considering school deprivation levels is limited. Therefore, we examined this in English Primary Schools. Methods: Participants ( $\mathrm{n}=409$ ) were students (9-10 years), from 13 schools. BMI and CRF (20 m shuttlerun) were measured at three time-points across the academic year and a fourth after summer recess. Results: BMI z-scores significantly decreased $(p=0.015)$ from autumn $(\mathrm{z}=0.336$ [CI 0.212 to 0.460$])$ to spring $(\mathrm{z}=0.252$ [CI 0.132 to $0.371])$, and then significantly increased $(p=0.010)$ to summer $(\mathrm{z}=0.327$ [CI 0.207 to 0.447]). CRF significantly increased $(p<0.001)$ from autumn $(\mathrm{z}=0.091$ [CI -0.014 to 0.196$])$ to spring $(\mathrm{z}=0.492$ [CI 0.367 to 0.616$])$, no change $(p=0.308)$ into summer $(\mathrm{z}=0.411$ [CI 0.294 to 0.528$])$, and a significant decrease $(p<0.001)$ into the following autumn term $(\mathrm{z}=0.125$ [CI 0.021 to 0.230$])$. BMI was unaffected by deprivation; however, pupils from the most deprived areas saw significantly greater reductions in CRF compared with pupils from affluent areas. Conclusion: Significant reductions in children's CRF occurred over the summer recess and was greater among children from schools in the most deprived areas. This may help inform future research into interventions targeting physical activity of school children, particularly over the summer recess.

Key words: Physical Fitness; Sport; Health Policy; Obesity

\section{INTRODUCTION}

Cardiorespiratory fitness (CRF) is modifiable by physical activity (PA) and independently associated with health [1], and higher academic attainment [2,3]; in children and adolescents. Evidence supports tracking CRF from childhood to adulthood [4], and that childhood CRF predicts adult cardiovascular disease and metabolic syndrome risk [5], highlighting the importance of maintaining and improving children's CRF [6]. Lang et al.

[7] proposed these factors considered together indicate that population status of $\mathrm{CRF}$ in children may help predict future non-communicable disease burden.

Cross-sectional data and metaanalyses have demonstrated rapid secular decline in CRF globally of around $0.36 \%$ per annum increasing in magnitude since 1970 [8]. Whilst public health agencies encourage novel interventions to increase childhood PA, widespread lack of routine health data hampers evaluation of their impact [9]. Indeed, the UK Chief Medical Officer has stated, "The introduction of a standardised school based fitness assessment in England may have multiple benefits that extend beyond the benefits for the individual" [10].

Currently, the only mandated measure of children's health status in England is the National Child Measurement Programme (NCMP [11]). The NCMP is an annual programme that measures height and weight of children in Reception (aged 4-5 years) and Year 6 (aged 10-11 years). Ease of implementation is a key consideration for school based measurement with height and weight easily measured to determine body mass index (BMI). Tracking of CRF levels 
should also follow a feasible and scalable approach.

The $20 \mathrm{~m}$ shuttle run test (20mSRT) is the most commonly employed field based measurement of CRF in children, is low cost, simple, and can test large groups simultaneously $[7,12,13]$. There is strong evidence the 20mSRT has criterion validity in children [12] and as a surveillance instrument could help identify populations with either low or high CRF (based upon international normative values for children [13]) and provide indicators that inform policy or intervention practice [7].

Physical fitness, including muscular power and CRF, increases from school year to school year [14]. Both BMI and CRF vary seasonally in children $[15,16]$ with increases seen throughout the school year $[16,17]$. However, improvements in CRF do not continue and are often lost over the summer recess [16,17]. Despite sedentary time and PA both potentially affecting BMI and CRF [18-21], the loss of CRF over the summer is particularly surprising as PA levels often increase during the summer periods [21].

Socioeconomic status also influences BMI with children from more deprived areas having greater obesogenic growth trajectories than more affluent peers [22-24]. Yet, PA levels and CRF may explain the impact of deprivation levels upon BMI [23,24]. Children from more deprived areas often have greater barriers to PA in general potentially influencing their BMI and CRF [25]. However, it is unknown whether seasonal variation seen in CRF, including the typical loss over summer holiday periods, is also influenced by deprivation levels. It may be that children from more deprived areas have greater barriers to summer PA opportunities [25] and thus, though in general children's PA levels increase through the summer [21], this may not be the case for those in more deprived areas.
Though there are currently programmes examining anthropometric measures in children in the UK, there is a lack of CRF testing in primary schools. Considering the importance of CRF, recent scoping work highlighted that it can be measured in schools in a simple scalable way using the $20 \mathrm{mSRT}$ [9]. In light of this and the seasonal variation seen in CRF, in addition to the current lack of research examining the impact of deprivation upon $\mathrm{CRF}$, the current study had the following aims:

1. To investigate the BMI and CRF in primary school pupils in North West England over a one-year period.

2. Examine the impact of school deprivation levels upon $\mathrm{CRF}$ and BMI.

\section{METHODS}

\section{Participants}

Participants were $(n=409)$ children aged 9-10 (Mean \pm SD; Height $132 \pm 6 \mathrm{~cm}$, Weight $30.75 \pm 7.15 \mathrm{~kg} ; 222$ males and 187 females) from 13 schools in North West England. Uptake to the testing at the individual level was $100 \%$ from children in the age groups tested across the schools involved. Participants were recruited through schools' involvement with the investigation, and schools were themselves recruited via National Teaching Schools in the local area and existing links with Premier Sport. All schools approached agreed to participate in the investigation.

\section{Ethics and informed consent}

As the result of guidance from our institutional ethics panel, the protocol of the present investigation deviated from existing procedures for governance of child measurement. The norm is for schools to opt in to an investigation and provide consent on behalf of pupils with parents provided the opportunity to opt their children out of the investigation. In the present investigation schools and 
parents/guardians were required to provide consent and opt in to the investigation. Institution ethics was granted for this study by the ethics committee at Aberystwyth University. Consent was obtained from schools and subsequently parents/guardians of all potential participants. Children were provided the opportunity to not participate in testing sessions if they did not wish to. This model was been developed through consultation with Public Health England and the Office for Standards in Education, Children's Services and Skills (Ofsted).

\section{Confidentiality}

All data were anonymised immediately following collection and stored on secure systems approved by Ofsted. Opt-out forms and paper files were stored in locked cabinets within schools, and electronic files stored on password protected computers, in both cases in accordance with the Ofsted information governance team. All files were destroyed upon completion of the investigation. Data were anonymised when transferred to the research team, and stored on password protected computers.

\section{Measures}

All testing was completed by in-situ service staff delivering curricular PE lessons and other extra-curricular physical activities in schools. All staff were employees of Premier Sport. This organisation was identified as being well placed to deliver the fitness testing described above on the scale necessary as they were already situated in the schools included in the study and delivering the 20m-SRT as part of their core business. Measurements were taken at four time points throughout a single calendar year: autumn term (October 2014), spring term (March 2015), summer term (June 2015), and the following autumn term (October 2015). All protocols and procedures were overseen by a member of the research team at the first time point, and thereafter random visits made to ensure standard protocols were followed. Further, delivery staff were provided with standard electronic forms to record all data.

BMI: Height was measured to the nearest centimetre and weight measured to the nearest $0.1 \mathrm{~kg}$. Body Mass Index (BMI) was calculated from height and weight scores $\left(\mathrm{kg} \cdot \mathrm{m}^{2}\right)$. BMI $\mathrm{z}$-scores specific to age and sex were calculated using UK 1990 growth reference data [26]. International Obesity Task Force (IOTF) classifications were then established [27].

Fitness: The 20mSRT was conducted involving $20 \mathrm{~m}$ shuttles starting at an initial speed of $8.5 \mathrm{~km} \cdot \mathrm{h}^{-1}$ increasing by $0.5 \mathrm{~km} \cdot \mathrm{h}^{-1}$ each minute. An audible signal indicated when a participant should initiate each shuttle. The final shuttle was recorded once a participant failed to maintain the audible controlled pace or stopped due to volitional exhaustion. End speed $\left(\mathrm{km} \cdot \mathrm{h}^{-1}\right)$ was determined by the final stage of the 20-mSRT based on the number of completed shuttles. The speed for the final completed stage was used as the end speed [28]. Age and sex specific z-scores were calculated using age global reference values for children [13].

Area-Level Deprivation: The arealevel deprivation of each school was classified using the English Index Deprivation 2015 (EID) [29] obtained from the school post-code (zip-code). The EID is a multidimensional measure of relative deprivation for small areas in England. The UK Government ranks areas based on decile of EID score (from decile 1 representing areas with the highest level of deprivation to decile 10 - the lowest). Areas falling in EID deciles 1 and 2 are considered deprived with area-level deciles 9 and 10 considered non-deprived (affluent). Participants were grouped from "Most Deprived" (deciles 1-2; $n=153$ ), "Mid Deprived" (deciles 3-8; $n=124$ ), to "Least Deprived" (deciles 9-10; $n=132$ ). 


\section{Data treatment.}

Missing data resulted at some time points due to child sickness, injury, or absence from school on the day of testing. The last observation carried forward (LOCF) method was used to provide a full data set. LOCF was used if a participant had two or more data entries producing a total sample of 409 for analysis. The total number of missing points, interpolated points, and comparison between the groups before and after data treatment are presented in the supplementary material. Independent samples t-test indicated no statistical difference between the original data and LOCF data, therefore only the 409 participants with full data were used in subsequent analysis.

\section{Statistical Analysis.}

Data were analysed using IBM

SPSS Statistics 24 for Windows (IBM., Chicago, IL.). Significance was accepted at an $\alpha$ level of $p \leq 0.05$. Assumptions of sphericity were examined using Mauchly's Test of Sphericity. A two-way 'time' $x$ 'group' ANOVA was used to compare main effects for 'time' (Autumn 2014, Spring 2015, Summer 2015, Autumn 2015), 'group' (Most Deprived, Mid Deprived, Least Deprived), and 'time' $\mathrm{x}$ 'group' interaction effects. Where sphericity was violated a GreenhouseGeisser correction used. Post hoc pairwise using bonferroni adjusted confidence intervals were performed usingestimated marginal means.

\section{RESULTS}

\section{Body Mass Index}

IOTF classifications are reported in Table 1 . The majority of participants were classified as normal weight. For BMI, ANOVA revealed a significant effect by

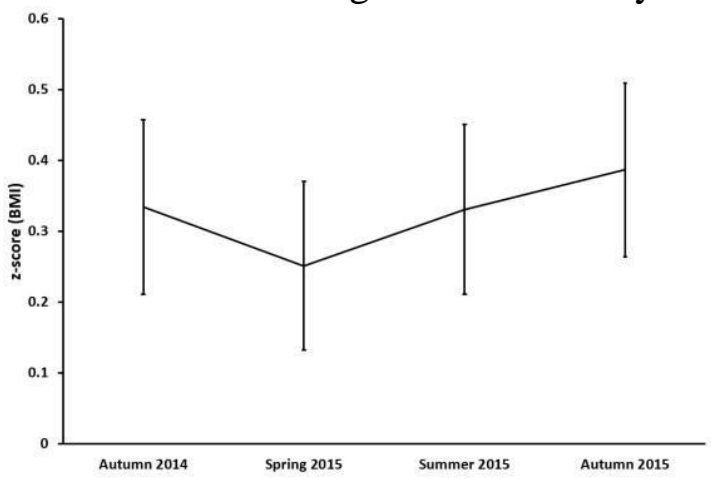

Figure 1. Mean BMI z-scores and 95\%CIs by time point for entire sample

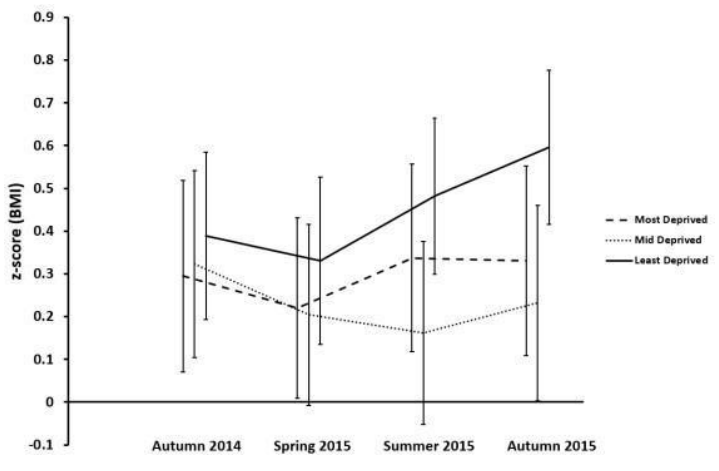

Figure 2. Mean BMI z-scores and 95\%CIs by time point grouped by deprivation level

'time' $\left(F_{(2.393,971.538}=6.469, p=0.001\right)$, though no significant effect by 'group' $\left(F_{(2,406)}=1.171, p=0.311\right)$. There was a significant 'time' $\mathrm{x}$ 'group' interaction effect $\left(F_{(4.786,971.538)}=3.916, p=0.002\right)$, though no significant post hoc pairwise comparisons at any time point. BMI

\begin{tabular}{|c|c|c|c|c|c|c|c|c|}
\hline \multirow[b]{2}{*}{ Grade } & \multicolumn{2}{|c|}{ Autumn 2014} & \multicolumn{2}{|c|}{ Spring 2015} & \multicolumn{2}{|c|}{$\overline{\text { Summer } 2015}$} & \multicolumn{2}{|c|}{ Autumn 2015} \\
\hline & $\%$ & $\mathrm{n}$ & $\mathrm{n}$ & $\%$ & $\mathrm{n}$ & $\%$ & $\mathrm{n}$ & $\%$ \\
\hline$\overline{\text { Underweight (BMI <18.5 kg.m²) }}$ & $8.1 \%$ & 33 & 41 & $9.0 \%$ & 35 & $8.6 \%$ & 35 & $8.6 \%$ \\
\hline Normal weight (BMI 18.5 to $<25 \mathrm{~kg} \cdot \mathrm{m}^{2}$ ) & $68.9 \%$ & 282 & 285 & $69.7 \%$ & 286 & $69.9 \%$ & 276 & $67.5 \%$ \\
\hline Overweight (BMI 25 to $<30 \mathrm{~kg} \cdot \mathrm{m}^{2}$ ) & $14.9 \%$ & 61 & 60 & $14.7 \%$ & 64 & $15.6 \%$ & 70 & $17.1 \%$ \\
\hline Obesity (BMI > 30 kg. $\mathrm{m}^{2}$ ) & $8.1 \%$ & 33 & 23 & $5.6 \%$ & 24 & $5.9 \%$ & 28 & $6.8 \%$ \\
\hline
\end{tabular}


significantly decreased $(p=0.015)$ from autumn $(\mathrm{z}=0.336$ [CI 0.212 to 0.460$])$ to spring ( $\mathrm{z}=0.252$ [CI 0.132 to 0.371 ]), and then significantly increased $(p=0.010)$ to summer $(\mathrm{z}=0.327$ [CI 0.207 to 0.447]). Thus there were no significant differences between the first and following autumn terms $(p>0.999)$. Figure 1 shows mean zscores over time for BMI and figure 2 shows BMI z-scores by deprivation group.

\section{Cardiorespiratory Fitness}

For CRF, ANOVA revealed a significant effect by 'time' $\left(F_{(2.868,1164.256)}=\right.$ 41.043, $p<0.001)$, a significant effect by 'group' $\left(F_{(2,406)}=4.351, p=0.013\right)$, and a significant 'time' $\mathrm{x}$ 'group' interaction effect $\left(F_{(5.735,1164.256)}=5.987, p<0.001\right)$. CRF significantly increased $(p<0.001)$ from autumn $(\mathrm{z}=0.091$ [CI -0.014 to $0.196])$ to spring $(\mathrm{z}=0.492$ [CI 0.367 to $0.616])$, no change $(p=0.308)$ into summer $(\mathrm{z}=0.411$ [CI 0.294 to 0.528$])$, and $\mathrm{a}$ significant decrease $(p<0.001)$ into the following autumn term $(\mathrm{z}=0.125$ [CI 0.021 to 0.230$])$. Thus there were no significant differences between the first and following autumn terms $(p>0.999)$. Figure 3 shows $\mathrm{z}$-scores over time for CRF.

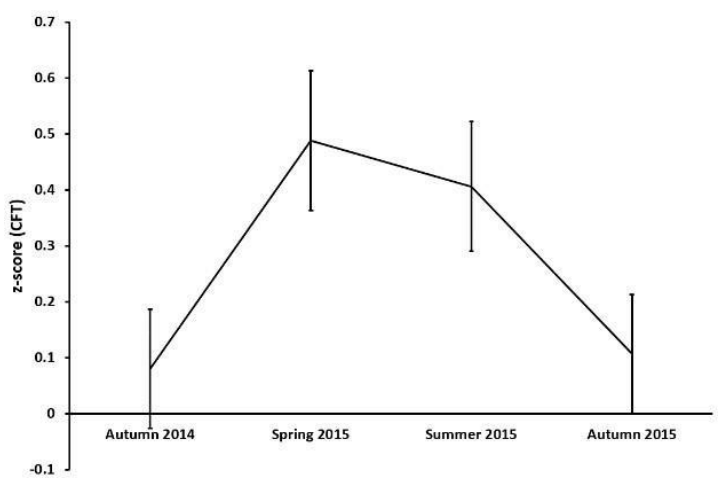

Figure 3. Mean CRF z-scores and 95\%CIs by time point for entire sample

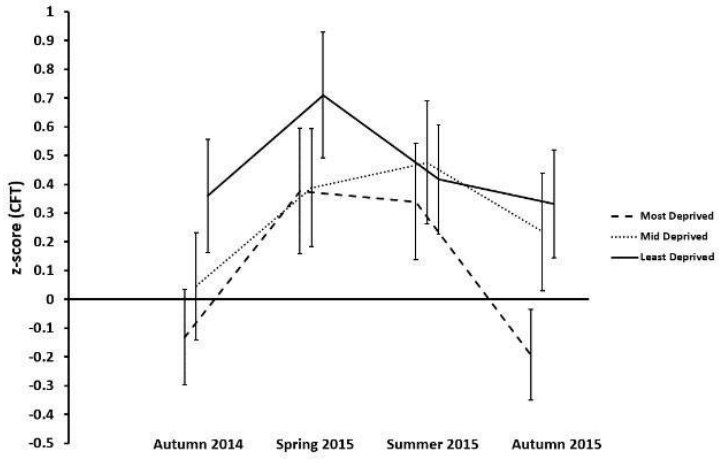

Figure 4. Mean CRF z-scores and 95\%CIs by time point grouped by deprivation level

Post hoc pairwise comparisons revealed pupils in the Most Deprived group had significantly lower CRF compared with the Least Deprived group in the autumn $(p<$ $0.001)$. In the spring and summer there were no differences between groups. However, in the following autumn pupils in the Most Deprived group had significantly lower CRF compared with the Least Deprived group ( $p$ $<0.001)$ and the Mid Deprived group ( $p=$ 0.003). Figure 4 shows CRF scores by deprivation group.

\section{DISCUSSION}

\section{Main Findings - BMI, CRF, and Deprivation Levels}

The primary purpose of this investigation was to examine BMI and CRF of children over a one-year period including academic year and summer recess, and the influence of school deprivation levels upon this. CRF increased $(+3.8 \%$ end speed for 20-mSRT) from autumn to spring and was maintained throughout the school year. However, CRF levels decreased (-2.3\% end speed for 20-mSRT) over the summer holidays to a level similar to the previous autumn. Maturation may impact CRF however normative data indicate an annual increase in boys and girls 9-10 years of age [13] so was unlikely to have caused the variation seen. Further, climate correlates with 20mSRT performance with higher CRF in colder countries [7] though was also unlikely to have caused the variation as meteorological data of the nearest UK 
station suggests mean temperature remained $<20^{\circ} \mathrm{C}$ over the summer [30]. CRF changes were compounded by school area deprivation level increasing towards spring and decreasing over summer in all deprivation groups, yet with schools in the poorest areas diverging from others post summer recess. The Most Deprived group had initially lower CRF suggesting there may be the greatest potential for improvement in these children, yet similarly the greatest potential for CRF loss over the summer. BMI followed a similar pattern with initial decreases followed by increases over the year such that BMI was similar at both the beginning and end of the academic year and summer recess. BMI however was relatively unaffected by deprivation level. These findings may have implications for policy makers and those responsible for the health and wellbeing of children. Firstly, from a positive perspective, school based PA delivery programmes may be positively impacting upon CRF of children during the academic year. Indeed, children from schools in all deprivation levels increased CRF. Such increases are not dissimilar from specific training to increase CRF in children ( 45\% [31]). Other work has reported CRF increases over the school year in Greek school children [16] and Carrel et al. [32] found a school based PA intervention in US children improved CRF over the school academic year. However, some studies show CRF plateaus over summer recess [31], and Carrel et al. [17] reported followup analysis that improvements from their intervention were eradicated during this period. Recent work on seasonal variation in PA levels suggest children are least active during the autumn and winter seasons [33], and PA levels increase consistently during the summer season [21]. It seems counterintuitive that children in the present study lost CRF over this period.

It appears moderate-vigorous PA rather than light PA is more strongly associated with sustained health, fitness, and wellbeing in children [1,3,34,35]. Indeed, a recent study reported reallocation of sedentary time to light or moderate PA was not associated with improved CRF whereas vigorous PA was [20]. Though PA tends to increase over the summer this is mainly due to increased moderate PA, whereas vigorous PA tends to vary far less [21]. Thus, building CRF during youth through vigorous PA should be a focus of school based and summer PA programs. Summer day camps may provide opportunities to increase vigorous PA by $15-18 \%$ [36] and as such could represent a potentially valuable intervention.

Although PA levels were not measured, a notable limitation, anecdotally parents of children in this study suggested accessible opportunities to keep children active are limited during school holidays, and often unaffordable or difficult to manage around working hours. This may be a barrier that is amplified for those from deprived areas [25] and involved in the greater loss of CRF in the most deprived children. As such, future work should examine whether interventions addressing barriers such as accessibility and cost can facilitate uptake in the most deprived.

\section{Limitations}

Although all students consented to participate, we did not have complete data for all time points. This was primarily due to sickness, injury, and school absence, though it is possible some children may have been absent because of awareness of the forthcoming testing. PA levels were not measured in this study and so it is also not clear whether changes in CRF were a result of PA levels. Further, deprivation was considered on the basis of school area. Individual participant level data was not available for deprivation levels. Some participants may have been based in areas outside of the schools that represented differing EID levels. Future work should consider this and also other factors 
indicative of deprivation level such as eligibility for free school meals. Lastly, this research was conducted in the North West of England. Thus the generalizability to other schools across England is not clear. Future work should similarly examine seasonal change in CRF in other areas of the $\mathrm{UK}$ and worldwide.

\section{CONCLUSION}

Our data highlight that, although CRF increases throughout the academic year, reductions in children's CRF levels occur over the summer holiday period - an effect which is significantly more apparent among children from the most deprived schools. As such, these results highlight a need for interventions aimed at increasing children's PA levels, particularly vigorous PA, targeted towards the summer holidays to maintain the improvements produced during the school year.

\section{ACKNOWLEDGEMENTS}

The authors wish to thank Premier Sport for their funding and support in the delivery of this investigation. Specific thanks goes to Luke Miles, Danny Melling, John Gorner, and Andy Heald without whom the data collection would not have been possible, and for their contribution to the conceptualisation of this manuscript. Further, we wish to acknowledge each of the schools that participated, the parents of the children for providing required consent, and of course the children themselves.

\section{REFERENCES}

1. Barker AR, Gracia-Marco L, Ruiz JR, et al. Physical actvity, sedentray time, TV viewing, physical fitness and cardiovascular disease risk in adolescents: The HELENA study. Int $J$ Cardiol. 2018; 254: 303-309 doi: 10.1016/j.ijcard.2017.11.080.

2. Sardinha LB, Marques A,
Minderico C, et al. Longitudinal relationship between cardiorespiratory fitness and academic achievement. Med $S c i$ Sports Exerc. 2016; 48(5): 839-844 doi:

10.1249/MSS.0000000000000830.

3. Oliviera T, Pizarro A, Costa M, et al. Cardiorespiratory fitness, but not physical activity, is associated with academic achievement in children and adolescents. Ann Hum Biol.

2017; 44(4): 309-315 doi:

10.1080/03014460.2017.1308010.

4. Ruiz JR, Castro-Piñero J, Artero EG, et al. Predictive Validity of HealthRelated Fitness in Youth: A Systematic Review. Br J Sports Med. 2009; 43(12): 909-923. doi:

\subsection{6/bjsm.2008.056499}

5. Malina RM, Physical activity and fitness: Pathways from childhood to adulthood. Am J Hum Biol.

2001;13:

$162-172$

doi:10.1002/15206300(200102/03)13:2 $<162:$ :AIDAJHB1025>3.0.CO;2-T

6. Case A, Fertig A, Paxson C. The lasting impact of childhood health and circumstance. J Health Econ. 2005; 24(2): 365-89

7. Lang JJ, Tremblay MS, Léger L,

Olds T, Tomkinson GR. International variability in $20 \mathrm{~m}$ shuttle run performance in children and youth: who are the fittest from a

50-country comparison? A systematic literature review with pooling of aggregate results. $\mathrm{Br} J$ Sports Med. 2018; 52: 276. doi: 10.1136/bjsports2016-096224

8. Tomkinson GR, Olds TS. Secular changed in pediatric aerobic fitness test performance: The global picture. In: Tomkinson GR, Olds TS, editors. Pediatric Fitness. Secular Trends and Geographic Variability. Med Sport Sci: Basel,

Karger; 2007, p. 46-66 
https://doi.org/10.1159/000101075

9. Domone S, Mann S, Sandercock G, Wade M, Beedie C. A Method by

Which to Assess the Scalability of

Field-Based Fitness Tests of

Cardiorespiratory Fitness Among

Schoolchildren. Sports Med. 2016;

46(12): 1819-1831 doi:

10.1007/s40279-016-0553-6.

10. Department of Heath. On the State of the Public Health. The 2009 Annual Report of the Chief Medical Officer. London, UK; Department of Health; 2010.

11. NHS Digital. National Child Measurement Programme [Internet]. NHS Digital; n.d.

Available from:

http://content.digital.nhs.uk/NCMP

12. Castro-Piñero J, Artero EG,

España-Romero $\mathrm{V}$, et al.

Criterionrelated validity of field-based

fitness tests in youth: a systematic

review. Br J Sports Med. 2010; 44:

934-943.

Doi:

10.1136/bjsm.2009.058321

13. Tomkinson GR, Lang JJ, Tremblay MS, et al. International normative $20 \mathrm{~m}$ shuttle run values from 1142026 children and youth representing 50 countries. Br J Sports Med 2017;

51: 1545-1554. Doi:

10.1136/bjsports-2016-095987.

14. Caldwell HA, Proudfoot NA, KingDowling S, Di Cristofaro NA, Cairney J, Timmons BW. Tracking of physical actviity and fitness during the early years. Apply Physiol Nutr Metab. 2016; 41(5):

504-510 doi: 10.1139/apnm-20150338

15. Moreno JP, Johnston CA, Chen T, et al. Seasonal variability in weight change during elementary school. Obesity. 2015; 23(2): 422-428

16. Christodoulos AD, Flouris AD, Tokmakidis SP. Obesity and physical fitness of pre-adolescent children during the academic year and the summer period: effects of organized physical activity. $J$ Child Health Care 2006; 10(3): 199-212

17. Carrel AL, Clark RR, Peterson S, Eickhoff J, Allen DB. School-based fitness changes are lost during the summer vacation. Arch Pediatr Adolesc Med. 2007; 161(6): 561-4.

doi:10.1001/archpedi.161.6.561

18. Sandercock GR, Ogunleye AA. Independence of physical activity and screen time as predictors of cardiorespiratory fitness in youth. Pediatr Res. 2013; 73(5): 692-697 doi: 10.1038/pr.2013.37.

19. Júdice PB, Silva AM, Berria J, Petroski EL, Ekelund U, Sardinha LB. Sedentary patterns, physical activity and healthreated physical fitness in youth: a crosssectional study. Int J Behav Nutr Phys Act. 2017; 14(1): 25 doi: 10.1186/s 12966-017-0481-3.

20. Santos DA, Marques A, Minderico CS, Ekelund U, Sardinha LB. A crosssectional and prospective analyses of reallocating sedentary time to physical activity on childrens cardiorespiratory fitness. J Sports Sci. 2017; Epub ahead of print. doi:

10.1080/02640414.2017.1411176.

21. Kornides ML, Rimm EB, Chavarro

JE, Gillman MW, Rosner B, Field AE. Seasonal variations in meeting physical activity recommendations and development of overweight during adolescence. Child Obes

2018; 14(1): 33-40

22. Nau C, Schwartz BS, BandeenRoche K, et al. Community socioeconomic deprivation and obesity trajectories in children using electronig health records. Obesity 2015; 23(1): 207-212

23. Nevill AM, Duncan MJ, Lahart I, Sandercock G. Modelling the association between weight status and social deprivation in English school children: Can physical activity and 
fitness affect the relationship? Ann Hum Biol. 2016; 43(6): 497-504.

24. Nevill AM, Duncan MJ, Lahart I, Sandercock G. Cardiorespiratory fitness and activity explains the obesitydeprivation relationship in children. Health Promot Int 2017;

Epub ahead of print. Doi: 10.1093/heapro/daw106.

25. Eyre EL, Duncan MJ, Birch SL, Cox VM. Low socio-economic environmental determinants of children's physical activity in Coventry, UK: A qualitative study in parents. Prev Med Rep 2014; 1: 32-42

26. Cole TJ, Freeman JV, Preece MA. Body mass index reference curves for the UK, 1990. Arch Dis Child. 1995; 73(1): 25-9.

27. Cole TJ, Bellizzi MC, Flegal KM, Dietz WH. Establishing a standard definition for child overweight and obesity worldwide: international survey. $B M J$. 2000; 320(7244): 1240-1243.

28. Léger LA, Mercier D, Gadoury C, Lambert J. The multistage 20 metre shuttle run test for aerobic fitness. $J$ Sports Sci. 1988; 6(2): 93-101.

29. Department for Communities and Local Government. The English Index of Multiple Deprivation (IMD) 2015 Guidance. London, UK: Department for Communities and Local Government; 2015. 7.

Available

from:

https://www.gov.uk/government/up loads/system/uploads/attachment_d ata/file/464430/English_Index_of_

Multiple_Deprivation_2015_Guidance.pdf

30. Met Office Web site [internet]. Exeter, UK: Met Office; (cited March 2018). Available from:

https://www.metoffice.gov.uk/pub/ data/weather/uk/climate/stationdata /bradforddata.txt
31. Baquet G, Van Praagh E, Berthoin S. Endurance training and aerobic fitness in young people. Sports Med. 2003; 33(15): 1127-1143.

32. Carrel AL, Clark RR, Peterson SE, Nemeth BA, Sullivan J, Allen DB. Improvement of fitness, body composition, and insulin sensitivity

in overweight children in a schoolbased exercise program: a randomized, controlled study. Arch Pediatr Adolesc Med. 2005; 159(10): 963-968

33. Atkin AJ, Sharp SJ, Harrison F, Brage $S$, van Sluijs EMF. Seasonal variation in children's physical activity and sedentary time. Med Sci Sports Exerc. 2014; 48(3): 449-456 doi: 10.1249/MSS.000000000000 0786

34. Gralla MH, McDonald SM, Breneman C, Beets MW, Moore JB. Associations of objectively measured vigorous physical activity with body composition, cardiorespiratory fitness, and cardiometabolic health in youth: A review. Am J Lifestyle Med. 2016; Epub ahead of print doi.org/10.1177/155982761562441 7

35. Aires L, Silva P, Silva G, Santos MP, Ribeiro JC, Mota J. Intensity of physical activity, cardiorespiratory fitness, and body mass index in youth. $J$ Phys Act Health. 2010; 7(1): 54-59

36. Beets MW, Weaver RG, Beighle A, Webster C, Pate RR. How physically active are children attending summer day camps? $J$

Phys Act Health 2013; 10(6): 850855 